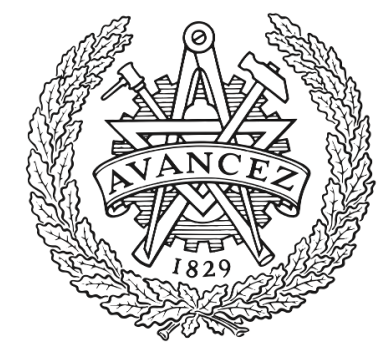

CHALMERS

UNIVERSITY OF TECHNOLOGY

\title{
Congestion Management using Local Flexibility Markets: Recent Development and Challenges
}

Downloaded from: https://research.chalmers.se, 2023-04-26 11:07 UTC

Citation for the original published paper (version of record):

Bouloumpasis, I., Steen, D., Le, A. (2019). Congestion Management using Local Flexibility Markets:

Recent Development and Challenges. Proceedings of 2019 IEEE PES Innovative Smart Grid

Technologies Europe, ISGT-Europe 2019, 2019.

http://dx.doi.org/10.1109/ISGTEurope.2019.8905489

N.B. When citing this work, cite the original published paper. 


\title{
Congestion Management using Local Flexibility Markets: Recent Development and Challenges
}

\author{
Ioannis Bouloumpasis, David Steen, Member, IEEE and Le Anh Tuan, Member, IEEE \\ Department of Electrical Engineering \\ Chalmers University of Technology \\ 41296 Gothenburg, Sweden \\ Email: \{ioannis.bouloumpasis, david.steen, tuan.le\}@chalmers.se
}

\begin{abstract}
Increasing amount of renewable based distributed generation at distribution systems, leads to an increased need for active distribution network management dealing with local network congestion and voltage issues. Development of local flexibility markets aims to provide a market-based solution to these issues. This paper presents a comprehensive review of proposed approaches towards markets exploiting the flexibilities from the demand-side. Efforts have been made on presenting a systematic overview of market design, including e.g. framework, participation, bidding and clearing mechanisms, of local flexibility market proposals developed in recent years. The implementation and regulatory issues and challenges are also discussed. The paper also presents the conceptual framework of the local flexibility service market which is currently being developed within UNITED-GRID project. This proposal aims to provide a holistic approach on local service markets, so that Distribution System Operators (DSOs) are provided with a market-based instrument to manage their networks efficiently.
\end{abstract}

Index Terms-Congestion management, distribution network, local flexibility markets, UNITED-GRID, voltage management.

\section{INTRODUCTION}

Large-scale integration of renewable-based distributed generations (DGs), mainly Photovoltaic arrays (PV) and Wind Turbines (WT), and new and unpredictable types of loads such as Electric Vehicles (EVs) and Heat Pumps (HPs) in distribution grids is expected to cause network congestion and voltage problems in them [1], [2]. Network congestion can be defined as a situation that the demand for active power exceeds grid's transfer capability [3]. Congestion has usually been managed in transmission level, but it is expected to be an issue for DSOs, due to increasing renewable generation in distribution systems, causing e.g., bidirectional and unpredictable power flows [4]. Thus, many scientific efforts have focused on distribution congestion management [1]-[6].

Distribution congestion is usually mitigated by DSOs through grid reinforcement (increasing power lines, feeders and transformers capacity) [7]. This approach will result in increased costs for the DSOs. Furthermore, methods used for transmission congestion relief may not lead to desired results in distribution, as dispatching is more complex in distribution networks due to high penetration of small scale DGs with volatile output [8]. Voltage management is another important issue in modern distribution networks. According to the European Standard EN50160, the 10 minutes voltage deviation should not exceed $\pm 10 \%$ of its nominal value on a weekly basis [9]. However, volatile Renewable Energy Sources (RES) and new unpredictable loads in distribution level may cause higher deviations.

Flexibility services can be used for congestion and voltage management [10]-[16]. Generally, flexibility can be defined as the modification of generation and/or consumption in reaction to external price or activation signal in order to provide a service [14]. Flexibility can cover several needs regarding stability, frequency and energy supply. In local level, flexibility for transfer capacity and voltage management can be employed to effectively avoid system bottlenecks and keep voltage between limits. In these cases, the activation time of flexibility services could vary from seconds to several hours [17]. Flexibility-related solutions are highly important for future power systems [17], especially in distribution level, as flexibility provides an economical and efficient alternative to DSOs for proper management of their systems.

Different methods regarding the use of flexibility have been proposed, such as dynamic pricing and dynamic tariffs [18]. However, local flexibility markets for congestion-related services seems the most promising concept, providing financial and operational benefits for system operators and flexibility providers [19]. Different research (e.g. [8], [20][26]) and commercial (e.g. [27]-[30]) approaches have been recently proposed, targeting flexibility trade for efficient distribution network operation. According to their perspective, they focus on congestion, voltage and/or imbalance management. The volume of different approaches calls for systematic classification of market frameworks and their aims.

The main contributions of this paper include:

- Provision of a systematic classification of recent research and commercial flexibility market proposals, with focus on different targets, framework, time-line, bidding and clearing.

The work leading to this paper was part of the UNITED-GRID project which has received funding from the European Union's Horizon 2020 Framework Programme under Grant Agreement No 773717. 
- Comprehensive discussions of important issues and barriers for local flexibility market implementation, focusing on timing, customers' and DSO's role, and the potentially necessary changes in the regulatory framework.

- Provision of the conceptual market framework being developed in UNITED-GRID project [31].

The remaining of the paper is as follows: In Section II, recent research and commercial approaches on flexibility markets are presented along with the most important issues and barriers regarding local flexibility market implementation. In Section III the conceptual framework of the local service market being developed in UNITED-GRID project is analyzed. Finally, in Section IV conclusions are drawn.

\section{FLEXIBILITY MARKETS: APPROACHES AND BARRIERS}

Many scientific papers and research projects have targeted local flexibility market development. Most approaches converge to the need of aggregators that could facilitate integration of lower capacity DGs [8]. However, different approaches have been proposed regarding trading horizon, bidding and clearing mechanisms. Other options than marketplaces can be used for flexibility exchange such as direct bilateral agreements or block-chain and peer-to-peer flexibility trade (e.g. Brooklyn microgrid [32]). However, the primary focus of this paper is local flexibility markets and peer-to-peer approaches are not discussed. Comprehensive literature reviews on flexibility use are made in [12] and [13].

\section{A. Market designs}

In this subsection, the most significant characteristics of recent research projects are presented.

\section{1) Overview and targeting}

In iPower [8], [20], [21] a flexibility market based on a Flexibility Clearing House (FLECH) is proposed. It operates in parallel with existing markets, trading flexibility services between flexibility providers and DSO. FLECH is responsible for contracts and monetary transactions between DSO and aggregators. Flexibility services for congestion and voltage management are traded, while balancing services are not catered. In EMPOWER [22]-[24] the creation of a community for energy and flexibility exchange is proposed. Smart Energy Service Provider (SESP) is the market operator for energy and flexibility trade among community members and the central market, aiming, amongst others, the provision of congestion and voltage management services to DSO. Furthermore, SESP acts as an aggregator, representing the community in central market. A similar market concept has been adopted in INVADE project [25]. In SmartNet flexibility use for realtime imbalances is proposed and congestion management is a byproduct. Thus, capacity services are not catered [26].

\section{2) Time-line}

In iPower, long-term services are traded, where DSO procures flexibility reservation and then activates the required service, if necessary, according to contracts. Long-term approach ensures both capacity reservation and stable financial income for participants. However, there is no solution for forecasting failures or emergencies. In
EMPOWER, short-term services are traded, but there is no provision for real-time flexibility services despite the 15minute window, as the general flexibility plan is submitted the previous day. In SmartNet, real-time imbalance services are traded, thus auctions are conducted with high frequency resolution (5 minutes).

\section{3) Trading and clearing mechanisms}

In iPower two trading approaches are proposed; a SingleSide Auction (SSA) where DSO is the only buyer and aggregators are flexibility providers; and a supermarket approach where aggregators forecast DSO needs for flexibility and make their offers. In both cases a pay-as-clear approach is used. Furthermore, bilateral contracts are proposed to stipulate participation at initial stages [21]. In EMPOWER, SESP receives DSO's flexibility demands and operates a local market to gather the required flexibility. SESP submits community's flexibility schedule for the next day in 15minutes resolution window to the DSO. If it is accepted, SESP makes contracts with the DSO and flexibility providers using a pay-as-bid approach [24]. Alternative trading mechanisms are proposed, such as price-scan auction and reverse English auction. In SmartNet, an auction-based trade is proposed, while there is provision for both simple and complex bids.

Table I shows the most significant details of these projects.

TABLE I. RECENT FLEXIBILITY MARKET PROJECT CHARACTERISTICS

\begin{tabular}{ccccc}
\hline Project & Target & Time-line & Trading & Clearing \\
\hline $\begin{array}{c}\text { iPower [8], } \\
{[20],[21]}\end{array}$ & $\begin{array}{c}\text { Congestion } \\
\text { \& voltage }\end{array}$ & $\begin{array}{c}\text { Long- } \\
\text { term }\end{array}$ & $\begin{array}{c}\text { Bilateral/SSA/ } \\
\text { supermarket }\end{array}$ & $\begin{array}{c}\text { Pay-as- } \\
\text { clear }\end{array}$ \\
$\begin{array}{c}\text { EMPOWER } \\
{[22]-[24]}\end{array}$ & $\begin{array}{c}\text { Congestion } \\
\& \text { voltage }\end{array}$ & $\begin{array}{c}\text { Short- } \\
\text { term }\end{array}$ & $\begin{array}{c}\text { Auctions/ } \\
\text { bilateral }\end{array}$ & $\begin{array}{c}\text { Pay-as- } \\
\text { bid }\end{array}$ \\
$\begin{array}{c}\text { SmartNet } \\
{[26]}\end{array}$ & Imbalance & Real-time & Auctions & $\begin{array}{c}\text { Pay-as- } \\
\text { clear }\end{array}$ \\
\hline
\end{tabular}

B. Commercial platforms for flexibilty services

In this subsection, the main characteristics of recent commercial flexibility platforms are presented.

NODES [27] provides an independent marketplace for decentralized flexibility trade. Flexibility buyers such as TSOs, DSOs and Balance Responsible Parties (BRPs) procure flexibility services from flexibility providers (aggregators, microgrids and other BRPs), to manage congestion and imbalances. IO.Energy Ecosystem [28] is an initiative built by system operators aiming the development of energy services towards customer-based power systems. It provides a cooperation platform among participants targeting benefits for all involved actors. Universal Smart Energy Framework (USEF) [29] has developed a functional market framework for energy and flexibility trade along with the necessary tools and rules for its robust implementation. USEF provides a detailed framework in which all participants' role is clarified. Piclo [30] provides the marketplace for flexibility services in United Kingdom enhancing visibility of network congestion areas to help flexibility providers planning.

Table II summarizes the above commercial approaches on flexibility trade. 
TABLE II. COMMERCIAL FLEXIBILITY APPROACHES

\begin{tabular}{ccccc}
\hline Platform & Buyers & Sellers & Target & Time-line \\
\hline $\begin{array}{c}\text { NODES } \\
{[27]}\end{array}$ & $\begin{array}{c}\text { TSO, } \\
\text { DSO, } \\
\text { BRPs }\end{array}$ & $\begin{array}{c}\text { Aggregators, } \\
\text { BRPs, } \\
\text { Microgrids }\end{array}$ & General & $\begin{array}{c}\text { Long-term, } \\
\text { day-ahead, } \\
\text { intraday }\end{array}$ \\
$\begin{array}{c}\text { IO.Energy } \\
\text { Ecosystem } \\
\text { [28] }\end{array}$ & All & $\begin{array}{c}\text { Prosumers, } \\
\text { BRPs }\end{array}$ & General & $\begin{array}{c}\text { Mostly real- } \\
\text { time }\end{array}$ \\
$\begin{array}{c}\text { USEF [29] } \\
\text { DSO, }\end{array}$ & ARPs, & Aggregators & General & $\begin{array}{c}\text { Short-term, } \\
\text { long-term }\end{array}$ \\
& TSO & & & Gong-term \\
Piclo [30] & DSO & Prosumers & General & Long \\
\hline
\end{tabular}

\section{Implementation issues and barriers}

This subsection presents some of the most significant issues and barriers for local flexibility market implementation.

\section{1) Time-line and real-time services}

As shown in Table I, time-line depends on the perspective. Some proposals, focus on grid reinforcement mitigation, providing long-term capacity reservation to ensure availability of flexibility services, that can be activated closer to real-time, if necessary [7], [8]. The reserved capacity that is available through the long-term market can be activated via a short-term market. Other approaches propose day-ahead planning with intra-day hourly dispatch and specific time window resolution [16], [19], [24]. Finally, other approaches state the necessity of real-time services for imbalance, congestion and voltage management [14], [26], [33]. Real-time services increase local flexibility market efficiency, as the risk of emergencies and forecasting errors on day-ahead or long-term level is compensated. In addition, voltage management should be performed to close-to-real-time conditions, according to [9], as a 10-minute window is referred. Most real-time approaches specify a 15-minute window, except for those that manage real-time imbalances. Thus, with current regulation, 10-15 minutes time resolution seems sufficient.

\section{2) Customer role}

Customers' role in local flexibility markets has not been clarified. An increasing number of private customers install loads with the potential to be flexible (HPs, EVs etc.) and DGs (e.g. PVs), changing their status from passive consumers to prosumers and flexibility providers. Customers' participation in wholesale markets is hindered by the lowest acceptable bid limit. In local flexibility markets, this problem can be overcome by enforcing lower bid limits and by introducing aggregators that will make contracts with end-users and represent them in local markets.

\section{3) Implementation barriers}

Many issues should be addressed prior to local flexibility market implementation. DSOs are skeptical about relying on flexibility services to solve security of supply issues in the longer-term [34]. Moreover, DSOs are hesitant about local flexibility markets due to illiquidity and lack of customer participation [34]-[36]. Flexibility in customer mind is significant for flexibility markets. Customers should be financially and socially incentivized to accept sacrificing their convenience to provide flexibility services. Long-term contracts and product standardization are expected to enhance market's liquidity and encourage customer participation [37]. Moreover, informational campaigns could enhance customer awareness about flexibility usefulness and the social benefits of their active participation in local markets. Changes should be made in the existing regulatory framework, so that DSOs can facilitate flexibility trade through local market structures.

\section{The future role of DSOs and required changes in regulatory framework}

DSO future role in flexibility markets and the necessary regulatory changes are significant issues to be addressed.

\section{1) Current DSO role and regulators perspective}

Generally, DSOs should act as neutral market facilitators that should not interfere with market functioning by restricting consumption or production, for example regarding demand response [38]. Moreover, DSOs should guarantee system stability, power quality, technical efficiency and cost effectiveness [34]. From regulators' perspective DSOs should act as neutral market facilitators that enable flexibility services to develop. However, DSOs should not distort the potentially competitive market in flexibility services [39]. The respective regulatory framework should be non-discriminatory and not hinder or unduly disincentivize DSOs from facilitating the development of flexibility [35].

\section{2) DSOs perspective and required regularory changes}

E.DSO suggest that DSOs should act as neutral market facilitators and coordinators of all network customers due to the deep knowledge of their networks [36]. DSOs require legislation changes, amongst other, regarding prevention of double use of flexibility resources when used for congestion management [36]. They also recommend that each system operator (DSOs and TSOs) should make decisions in its own system, as they hold the remit and the responsibility for operating their own networks securely and reliably [36]. Moreover, suitable TSO-DSO coordination schemes should be established so that efficient and secure use of flexibility is guaranteed [26], [35], [36], [40]. The most significant issue is whether TSOs should participate in local flexibility markets.

\section{UNITED-GRID SERVICE MARKET FRAMEWORK}

In UNITED-GRID a local market framework for exchange of flexibility and other services is being developed. UNITEDGRID Service Market (UG-SM) aims to provide a robust market-based instrument to DSOs for congestion and voltage management. In this subsection, the preliminary framework of UG-SM will be presented.

\section{A. Market participants}

In UG-SM, the participants are: a) local DSO; b) UNITED-GRID Service Market Operator (UG-SMO); and c) aggregators representing prosumers, households with flexible loads, EVs, building and storage owners, and local DGs. UGSMO is responsible for: a) market activation; b) auctions; c) network constraints compliance; d) clearing; and e) contracts.

\section{B. Market modes}

Three different modes regarding timing are proposed: a) Long-term market for services forecasted in advance and 
needed for a specific period (e.g. the next year). In this mode flexibility reservation is traded, so that DSOs can procure flexibility capacity in areas with anticipated problems, while paying a reservation fee. In this case the possibility of multiple activations within the contracted period is included. Services can be activated, when needed, closer to real time and DSO pays an activation fee. This market is open from when a longterm service need is forecasted until a certain time (e.g. one or several months) before the date of the first possible activation. DSO should send the activation signal one day before service provision, if necessary. This market mode provides an alternative to grid reinforcement, while long-term contracts would encourage customer participation, enhancing market liquidity [37]; b) Short-term market for services forecasted for the following day that cannot be catered by long-term contracts. It is open for specific hours of the previous day (e.g. 12:00-23:59), where DSO can procure flexibility reservation for the next day. DSO should send activation signal $1 \mathrm{~h}$ before service provision, if necessary; and c) Real-time market for services for the following hour and emergencies that cannot be catered by long-term and short-term contracts. It is open until several minutes (e.g. 15 minutes) before service provision and DSO should send activation signal a few minutes (e.g. 5-10 minutes) before service initiation, if necessary, depending on the service type (e.g. voltage deviations could be handled in a 10-minute frame, while serious emergencies could require faster response). The interaction among different market modes is illustrated in Fig. 1.

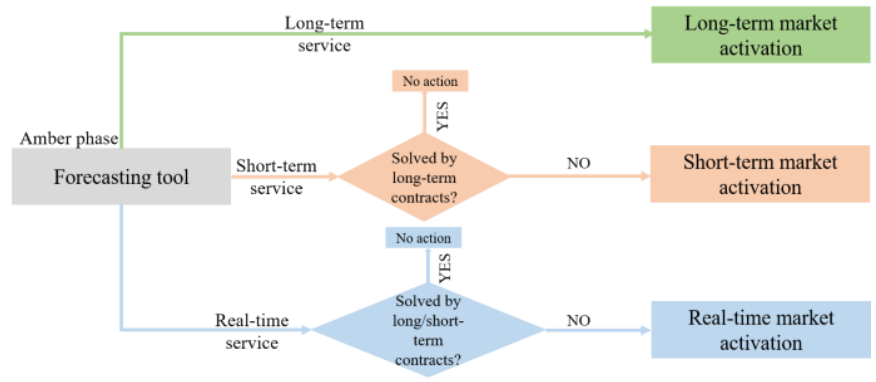

Figure 1. Local service market overview

\section{Market operation}

UG-SM is event driven according to the traffic light concept [41]. DSO constantly forecasts its future state and when a problem is detected (amber phase) it sends a signal to UG-SMO for market activation. When no problem is detected (green phase) the market is idle. In emergency cases and when no solution can be provided by market operation (red phase) DSO takes direct asset control to manage its network. When a service need is forecasted, DSO sends a signal to UG-SMO that activates the suitable market mode (long-term, short-term or real-time). Then, UG-SMO is responsible for the required auction. DSO's ask is published in open orderbooks accessible to all aggregators, where interested aggregators can place their bids. DSO's ask should include information about type, location, volume, duration and maximum price of the service.

\section{Trading and clearing mechanisms}

Indifferent of the market mode, when the auction deadline is reached, UG-SMO clears the market using SSA, as DSO is the only buyer. Aggregators' bids are ranked in increasing order and are getting accepted from the cheapest until DSO's requested volume is satisfied. The selected bids are checked with relation to grid constraints by an Optimal Power Flow (OPF) algorithm. Then, the market is cleared and accepted bids make contracts with DSO. A uniform price scheme is proposed where clearing price is the price of the most expensive bid accepted. A reservation fee is also included, which could be a percentage (e.g. 10\%) of the activation price (i.e. clearing price). Thus, each accepted bid will be compensated for both capacity and activation. All bids and details about clearing and monetary transactions should be published in the specific orderbook for transparency, after market clearing. Fig. 2 shows a long-term market operation example. Short-term and real-time market operation is similar.

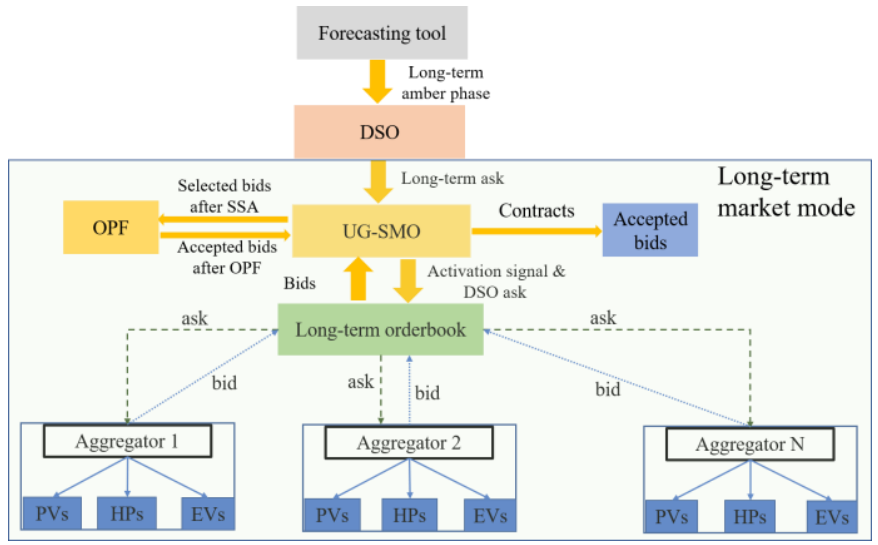

Figure 2. Example of long-term service market operation.

\section{E. UG-SM implementation and contribution}

UG-SM provides DSOs with a market-based instrument for holistic management of their systems in long-term, shortterm and real-time horizon, as it gives DSOs the opportunity to resort to it for all anticipated problems about congestion and voltage management, regardless of their time horizon. UG-SM long-term mode provides alternative to costly grid reinforcement, while short-term and real-time modes mitigate the risk of market failure and red phase operation. UG-SM real-time mode provides a time-window resolution suitable for real-time application. Moreover, long-term contracts and aggregator implementation are expected to incentivize smaller scale customer participation in UG-SM. Finally, UGSMO implementation mitigates the barriers derived by vague regulation about DSO role. UG-SMO can be either DSOoriented or independent entity, enhancing UG-SM future integration possibility. In addition, UG-SM design does not hinder TSO participation, given that bidding and clearing can be modified, and UG-SM could be also activated by TSOs.

\section{CONCLUSION}

In this work the most significant characteristics of local flexibility markets are presented and flexibility importance in distribution network management is explained. In addition, a systematic classification of recent research and commercial proposals about flexibility use is provided, focusing on bidding, clearing and trading horizon. In most markets, utilization of flexibility provides benefits to DSOs (reduced network issues, deferred investment requirement), while it 
provides financial and social benefits to market participants. Important issues and possible barriers about local flexibility market implementation are also illustrated. Vague regulatory framework along with customers' and DSOs' skepticism about participation in local flexibility markets are the main barriers to be overcome. Regulatory changes and participation incentives are expected to facilitate flexibility market implementation. Finally, the conceptual framework of a local service market being developed in UNITED-GRID project is analyzed. UG-SM provides DSOs with a holistic tool for efficient management of their systems in different time horizons, alleviating many local flexibility market barriers. In contrast to other approaches, DSOs can resort to UG-SM for any congestion and voltage issue regardless of its time-horizon (long-term, short-term or real-time).

\section{ACKNOWLEDGMENT}

The authors would like to thank Hjalmar Phil from Research Institutes of Sweden (RISE) for his comments on the paper.

\section{REFERENCES}

[1] T. Kornrumpf, J. Meese, M. Zdrallek, N. Neusel-Lange and M. Roch, "Economic dispatch of flexibility options for grid services on distribution level," in Proc. 2016 Power Systems Computation Conf., pp. 1-6.

[2] S. Huang and Q. Wu, "Real-time congestion management in distribution networks by flexible demand swap," IEEE Trans. Smart Grid, vol. 9, pp. 4346-4355, Sep. 2018.

[3] P. B. Andersen, J. Hu and K. Heussen, "Coordination strategies for distribution grid congestion management in a Multi-Actor, MultiObjective Setting," in Proc. 2012 IEEE PES Innovative Smart Grid Technologies Europe (ISGT Europe), pp. 1-8.

[4] D. B. Nguyen, J. M. A. Scherpen and F. Bliek "Distributed optimal control of smart electricity grids with congestion management," IEEE Trans. Autom. Sci. Eng., vol. 14, pp. 494-504, Apr. 2017

[5] A. Esmat, J. Usaola and M. A. Moreno, "Congestion management in smart grids with flexible demand considering the payback effect," in Proc. 2016 IEEE PES Innovative Smart Grid Technologies Europe (ISGT Europe), pp. 1-6.

[6] S. Huang, Q. Wu, Z. Liu and A. H. Nielsen, "Review of congestion management methods for distribution networks with high penetration of distributed energy resources," in Proc. 2014 IEEE PES Innovative Smart Grid Technologies Europe (ISGT Europe), pp. 1-6.

[7] K. Spiliotis, A. I. R. Gutierrez and R. Belmans, "Demand flexibility versus physical expansions in distribution grids," Applied Energy, vol. 182, pp. 613-625, Nov. 2016.

[8] C. Zhang, Y. Ding, N. C. Nordentoft, P. Pinson and J. Østergaard, "FLECH: A Danish market solution for DSO congestion management through DER flexibility services," Journal of Modern Power Systems and Clean Energy, vol. 2, pp. 126-133, Jun. 2014.

[9] CENELEC - EN 50160, Voltage characteristics of electricity supplied by public electricity networks, European Committee for Electrotechnical Standardization, CENELEC Std. Jul. 2010.

[10] C. Eid, P. Codani, Y. Chen, Y. Perez and R. Hakvoort, "Aggregation of demand side flexibility in a smart grid: a review for European market design," in Proc. 2015 European Energy Market Conf., pp. 1-5.

[11] A. Ramos, C. De Jonghe, V. Gomez and R. Belmans, "Realizing the smart grid's potential: Defining local markets for flexibility," Utilities Policy, vol. 40, pp. 26-35, Jun. 2016.

[12] J. Villar, R. Bessa and M. Matos, "Flexibility products and markets: literature review," Electric Power Systems Research, vol. 154, pp. 329340, Jan. 2018.

[13] S. Minniti, N. Haque, P. Nguyen and G. Pemen, "Local markets for flexibility trading: Key stages and enablers," Energies 2018, vol. 11, pp. 1-23, Nov. 2018. doi.org/10.3390/en11113074
[14] E. Amicarelli, T. Q. Tran and S. Bacha, "Flexibility service market for active congestion management of distribution networks using flexible energy resources of microgrids," in Proc. 2014 IEEE PES Innovative Smart Grid Technologies Europe (ISGT Europe), pp. 1-6.

[15] K. Knezovic, M. Marinelli, P. Codani and Y. Perez, "Distribution grid services and flexibility provision by electric vehicles: a review of options," in Proc. 2015 International Universities Power Engineering Conf. (UPEC), pp. 1-6.

[16] A. G. Madureira and J. A. P. Lopes, "Ancillary services market framework for voltage control in distribution networks with microgrids," Electric Power Systems Research, vol. 86, pp. 1-7, 2012.

[17] International Smart Grid Action Network (ISGAN) (2019) [online] Available at www.iea-isgan.org/flexibility-in-future-power-systems/

[18] O. Lutz, V. Olavarria, R. Hollinger, C. Wittwer and B. Koch, "Dynamic tariff design for a robust smart grid concept: An analysis of global vs. local incentives," in Proc. 2017 IEEE PES Innovative Smart Grid Technologies Europe (ISGT Europe), pp. 1-6.

[19] T. Kulms, A. K. Meinerzhagen and S. Koopmann, "Development of an agent-based model for assessing the market and grid oriented operation of distributed energy resources", Energy Procedia, vol. 135, pp. 294303, Oct. 2017.

[20] K. Heussen, D. E. M. Bondy, J. Hu, O. Gehrke and L. H. Hansen, "A clearinghouse concept for distribution-level flexibility services," in Proc. 2013 IEEE PES Innovative Smart Grid Technologies Europe (ISGT Europe), pp. 1-6.

[21] C. Zhang, et al., "A flex-market design for flexibility services through DERs" in Proc. 2013 IEEE PES Innovative Smart Grid Technologies Europe (ISGT Europe), pp. 1-6.

[22] E. Bullich-Massague et al., "Architecture definition and operation testing of local electricity markets. The empower project," in Proc. 2017 Modern Power Systems Conf., pp. 1-6.

[23] B. A. Bremdal, P. Olivella and J. Rajasekharan, "EMPOWER a network market approach for local energy trade," in Proc. 2017 IEEE Manchester PowerTech Conf., pp. 1-6.

[24] P. Olivella-Rosell et al., "Optimization problem for meeting distribution system operator requests in local flexibility markets with distributed energy resources," Applied Energy, vol. 210, pp. 881-895, Jan. 2018.

[25] P. Olivella-Rosell et al., "Local flexibility market design for aggregators providing multiple flexibility services at distribution network level," Energies 2018, vol. 11, pp. 1-19, Apr. 2018. doi.org/10.3390/en11040822.

[26] A. Ashouri et al., "Network and market models: preliminary report D2.4," SmartNet, Tech. Rep., Apr. 2017.

[27] Nodes (2019) [online] Available at: https://nodesmarket.com/

[28] IO.ENERGY ECOSYSTEM (2019) [online] Available at: https://ecosystem.ioenergy.eu/

[29] "THE FRAMEWORK EXPLAINED”, USEF, Tech. Rep., Nov. 2015.

[30] Piclo (2019) [online] Available at: https://piclo.energy/

[31] UNITED-GRID (2019) [online] Available at: https://united-grid.eu/

[32] The Brooklyn microgrid (2019) [online] Available at: https://www.brooklyn.energy/

[33] S. S. Torbaghan, N. Blaauwbroek, P. Nguyen and M. Gibescu, "Local market framework for exploiting flexibility from the end users," in Proc. 2016 European Energy Market Conf., pp. 1-6.

[34] "EURELECTRIC's vision about the role of Distribution System Operators (DSOs)", EURELECTRIC, Feb. 2016.

[35] "Flexibility use at distribution level," CEER, Jul. 2018.

[36] "Flexibility in the energy transition: A toolbox for electricity DSOs," European Distribution System Operators (E.DSO), Feb. 2018.

[37] Bundesverband Neue Energiewirtschaft e. V. "Decentralized flexibility market 2.0," Jul. 2016.

[38] I. Lehto, "The future role of DSOs and demand response," in 2018 German-Finnish Smart Grids Conf.

[39] "The future role of DSOs," CEER, Jul. 2015.

[40] Y. Tohidi, M. Farrokhseresht and M. Gibescu, "A review on coordination schemes between local and central electricity markets," in Proc. 2018 European Energy Market Conf., pp. 1-5.

[41] Bundesverband Neue Energiewirtschaft e. V. "Smart grid traffic light concept," Mar. 2015. 